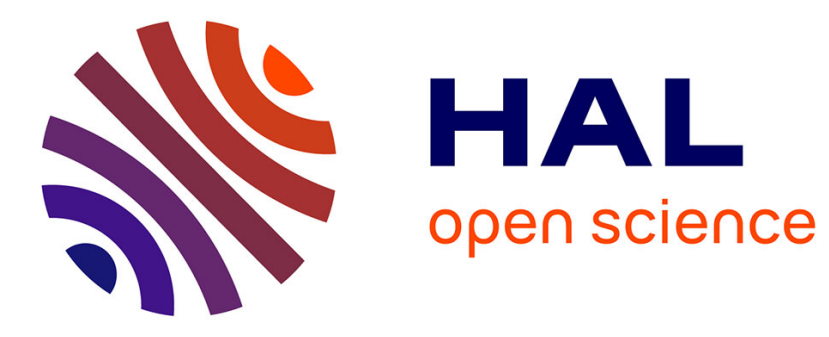

\title{
Glycine betaine mitigates cold stress damage in Chickpea
}

Harsh Nayyar, Krishan Chander, Sanjeev Kumar, T. Bains

\section{To cite this version:}

Harsh Nayyar, Krishan Chander, Sanjeev Kumar, T. Bains. Glycine betaine mitigates cold stress damage in Chickpea. Agronomy for Sustainable Development, 2005, 25 (3), pp.381-388. hal-00886283

\section{HAL Id: hal-00886283 https://hal.science/hal-00886283}

Submitted on 1 Jan 2005

HAL is a multi-disciplinary open access archive for the deposit and dissemination of scientific research documents, whether they are published or not. The documents may come from teaching and research institutions in France or abroad, or from public or private research centers.
L'archive ouverte pluridisciplinaire HAL, est destinée au dépôt et à la diffusion de documents scientifiques de niveau recherche, publiés ou non, émanant des établissements d'enseignement et de recherche français ou étrangers, des laboratoires publics ou privés. 


\title{
Glycine betaine mitigates cold stress damage in Chickpea
}

\author{
Harsh NAYYAR ${ }^{a *}$, Krishan CHANDER ${ }^{\mathrm{a}}$, Sanjeev KUMAR ${ }^{\mathrm{a}}$, T. BAINS ${ }^{\mathrm{b}}$ \\ a Department of Botany, Panjab University, Chandigarh 160 014, India \\ ${ }^{\mathrm{b}}$ Department of Plant Breeding, Panjab Agricultural University, Ludhiana 141 001, India
}

(Accepted 25 April 2005)

\begin{abstract}
Chickpea (Cicer arietinum L.) is sensitive to chilling temperatures $\left(<10{ }^{\circ} \mathrm{C}\right)$, especially in its reproductive phase. Consequently it suffers from floral abortion, poor pod set and reduced seed size, leading to substantial yield loss. The underlying mechanisms are yet to be elucidated, which are imperative to understand how to induce cold tolerance in this crop. Glycine betaine, a cryoprotectant, has been associated with induction of cold tolerance. In the present study, chickpea plants previously growing under the warm conditions of a glasshouse $\left(28 / 12{ }^{\circ} \mathrm{C}\right.$ as average maximum and minimum temperature, respectively) were subjected to the chilling stress of the field (12-14/3-5 $\left.{ }^{\circ} \mathrm{C}\right)$ at the (i) bud or (ii) pod-filling stages. Prior to exposure to stress, $1 \mathrm{mM}$ glycine betaine was applied exogenously for 3 consecutive days. In glycine betainetreated plants, chilling injury (assessed as electrolyte leakage) was reduced by 63\% while cellular respiration increased by 69\%. Application of glycine betaine at the bud stage resulted in improvement in flower functioning in terms of pollen germination (in vitro and in vivo), pollen viability, pollen tube growth, stigma receptivity and ovule viability. As a result, the floral retention, pod set and pod retention were increased by 47,38 and $23 \%$, respectively, over control. Treatment with glycine betaine at the pod-filling stage caused 30, 37, 46\% and $9 \%$ enhancement in seed yield/plant, number of seeds/100 pods, single-seeded pods/plant and individual seed weight, respectively, while number of doubleseeded pods was not affected significantly. Cold tolerance induced by glycine betaine appeared to be related to elevation of relative leaf water content, chlorophyll and sucrose, and decrease in abscisic acid as well as active oxygen species (malondialdehyde and hydrogen peroxide).
\end{abstract}

Cicer arietinum / chilling / floral abortion / glycine betaine / pod set

\section{INTRODUCTION}

Chilling $\left(<10^{\circ} \mathrm{C}\right)$ is highly detrimental to growth of chickpea (Cicer arietinum L.) particularly in its reproductive phase (Srinivasan et al., 1998). In northern parts of India, chickpea is grown as a winter-season crop where it experiences chilling and sometimes freezing injury during the vegetative and reproductive phases (Srinivasan et al., 1999). Early-maturing genotypes are extremely cold-sensitive (Singh et al., 1993) and show complete floral abortion and impaired pod filling (Nayyar et al., 2005) during chilling temperatures, leading to drastic reduction in yield. The mechanisms underlying cold injury are unknown in chickpea and very little information is available on this aspect (Nayyar et al., 2005). Earlier reports attributed coldinduced floral abortion to abnormal functioning of male and female gametes (Srinivasan et al., 1999) as well as restriction in pollen tube growth (Croser et al., 2003). We found higher abscisic acid and lower sucrose levels in aborted flowers of cold-stressed chickpea in comparison with retained ones (Nayyar et al., 2005).

Chilling stress is known to induce several abnormalities at various organizational levels of the cells. These include damage to membranes (assessed as electrolyte leakage) (Xing and Rajashekar, 2001), decrease in cellular respiration (Lee et al.,
1997), elevation of abscisic acid (Nayyar et al., 2005) and cryoprotectants such as sucrose and glycine betaine (Lee et al., 1997), increase in reactive oxygen species such as superoxide radicals, lipid peroxides and hydrogen peroxide, and concomitant increase in antioxidants such as ascorbic acid, glutathione, ascorbate peroxidase, catalase, superoxide dismutase, etc. (Kratsch and Wise, 2000).

Plants adapted to low temperature conditions accumulate certain molecules that have a cryoprotective role (Sakamoto and Murata, 2002). Glycine betaine is one such cryoprotective solute, which protects the activities of enzymes and proteins, stabilizes membranes (Rhodes and Hanson, 1993) and photosynthetic apparatus (Lee et al., 1997; McNeil et al., 1999) under chilling and freezing temperatures. Cold tolerance has been associated with accumulation of glycine betaine in several plant species (Kishitani et al., 1994). Moreover, genetically manipulated plants for higher glycine betaine production show enhancement of stress tolerance (Alia et al., 1997) that provides ample evidence for its involvement in defense response. In addition, exogenous application of glycine betaine has been reported to induce cold tolerance (Xing and Rajashekar, 2001). Possible roles for glycine betaine in stress tolerance include stabilization of complex proteins and membranes in vivo, protection of transcriptional and translational machinery, and acting

\footnotetext{
* Corresponding author: nayarbot@pu.ac.in and harshnayyar@hotmail.com, P.O. Box 1217, Panjab University, Chandigarh 160014, India
} 
as a molecular chaperone in the refolding of enzymes (Rhodes and Hanson, 1993). It also reduces the peroxidation of membrane lipids and protects electron transport via complex II in mitochondria (Chen et al., 2000). Plant species vary in their capacity to synthesize glycine betaine and some plants, such as spinach and barley, accumulate relatively high levels of glycine betaine in their chloroplasts while others, such as Arabidopsis and tobacco, do not effectively synthesize this compound (Sakamoto and Murata, 2002). Exogenously applied glycine betaine or the expression of transformed genes for endogenous glycine betaine synthesis increases salt (Mäkelä et al., 1998) and cold tolerance (Alia et al., 1998) in glycine betaine nonaccumulating plants.

Membrane damage due to chilling may occur due to direct effects of chilling on membranes or through action of reactive oxygen species (Kratsch and Wise, 2000) and can be assessed by measuring electrolyte leakage that is considered to be a reliable indicator of membrane injury in response to various kinds of stresses (Xing and Rajashekar, 2001). 2,3,5triphenyltetrazolium chloride reduction assay is used as a quantitative method in the evaluation of tissue viability. 2,3,5triphenyltetrazolium chloride is a water-soluble, colorless compound that can be reduced to water-insoluble red formazan by dehydrogenase systems (Roberts, 1951), primarily of respiration. The intensity and extent of 2,3,5-triphenyltetrazolium chloride staining are successfully employed to predict the germinability percentage of a sampled lot of seeds (Parker, 1995). In addition, 2,3,5-triphenyltetrazolium chloride reduction has been widely used in the viability assay of plant tissues exposed to stressful conditions (Lee et al., 1997). The reactive oxygen species such as hydrogen peroxide, superoxide and hydroxyl radicals are produced as a consequence of stress and reflect the intensity of stress experienced by the plants (Mittler, 2002). These reactive oxygen species are highly destructive to the cellular components of proteins, membrane lipids and nucleic acids (Mittler, 2002). Abscisic acid has been implicated in cold tolerance, possibly because of its regulatory effects on stress proteins and membranes (Lee et al., 1999). Carbohydrates, particularly sucrose, have been associated with cold hardiness in several herbaceous plants (Palonen et al., 2000).

In the present study, it was envisaged that cold sensitivity of chickpea might be related to endogenous glycine betaine levels and its functioning. Hence, we assessed the endogenous status of glycine betaine in a cold-sensitive chickpea genotype and subsequently treated the plants with glycine betaine to evaluate its effect on the reproductive phase in relation to yield. The endogenous status of some key indicators of chilling stress such as electrolyte leakage, cellular viability, abscisic acid, sucrose and active oxygen species was also examined in stressed and glycine betaine-treated plants with a view to find out the possible protective mechanisms.

\section{MATERIALS AND METHODS}

\subsection{Preliminary evaluation of glycine betaine concentration}

Chickpea (Cicer arietinum L.) seeds of an early-maturing genotype (ICCV 96029) were germinated at $23^{\circ} \mathrm{C}$ for $2 \mathrm{~d}$ in the dark in glass petri-dishes $(10 \mathrm{~cm})$ and later grown in halfstrength Hoagland's hydroponic medium for $7 \mathrm{~d}$ at $23{ }^{\circ} \mathrm{C}$ (light) $/ 20{ }^{\circ} \mathrm{C}$ (dark); $13 \mathrm{~h}$ (light) $/ 11 \mathrm{~h}$ (dark); irradiance $350 \mu \mathrm{mol} \mathrm{m} \mathrm{s}^{-1}$ at the surface of the plants. These 12-d-old seedlings were then subjected to $5^{\circ} \mathrm{C}\left(\mathrm{LT}_{50}\right)$ in the presence of $0.5,1.0,2.5,5.0$ and $10.0 \mathrm{mM}$ concentrations of glycine betaine incorporated into the growth medium $\left(15 \mathrm{~mL} \mathrm{plant}^{-1}\right)$ for evaluation of chilling injury. The $\mathrm{LT}_{50}$ temperature was chosen in a preliminary study by growing the seedlings at a range of temperatures $\left(1-10{ }^{\circ} \mathrm{C}\right)$. The $5{ }^{\circ} \mathrm{C}$ temperature was opted for the present study since it caused about $50 \%$ chilling injury (assessed as electrolyte leakage).

\subsection{Chilling injury}

Chilling injury was assessed as electrolyte leakage and with 2,3,5-triphenyltetrazolium chloride reduction assay as follows. Electrolyte leakage was measured using young root segments ( $1 \mathrm{~cm}$ in length) of five plants for each treatment (Lutts et al., 1996). Samples (1 g) were washed with deionized water to remove surface adhered electrolytes. These were placed in closed vials containing $10 \mathrm{~mL}$ of deionized water and incubated at $25^{\circ} \mathrm{C}$ on a rotary shaker for $24 \mathrm{~h}$, and subsequently the electrical conductivity of the solution $\left(\mathrm{L}_{1}\right)$ was determined. Samples were then autoclaved at $120{ }^{\circ} \mathrm{C}$ for $20 \mathrm{~min}$ and the final electrical conductivity $\left(\mathrm{L}_{2}\right)$ was obtained after equilibration at $25^{\circ} \mathrm{C}$. The electrolyte leakage $(\%)$ was calculated as $\left(\mathrm{L}_{1} / \mathrm{L}_{2}\right)$ $\times 100$.

2,3,5-triphenyltetrazolium chloride reduction assay was performed for each treatment (control and cold stress) using 6 replicates (Steponkus and Lanphear, 1967). The root segments ( $1 \mathrm{~g} ; 1 \mathrm{~cm}$ in length) collected from control and chilled seedlings were washed 3 times with sterile distilled water and blotted with filter paper. Three replicates of each treatment were incubated for $2 \mathrm{~min}$ in $1 \mathrm{~mL}$ of water at $95^{\circ} \mathrm{C}$ (heated samples). All the six replicates were then placed in glass tubes containing $4 \mathrm{~mL}$ of $50 \mathrm{mM}$ phosphate buffer $(\mathrm{pH} \mathrm{7.4)}$ with $0.4 \%(\mathrm{w} / \mathrm{v})$ 2,3,5-triphenyltetrazolium chloride. These were incubated for $20 \mathrm{~h}$ at $28{ }^{\circ} \mathrm{C}$ in darkness. The solution was drained, the segments were washed twice, $4 \mathrm{~mL}$ of ethanol was added and the tubes were vigorously shaken. The absorbance due to formazan formed in vivo was recorded at $485 \mathrm{~nm}$. The 2,3,5triphenyltetrazolium chloride reduction was expressed in terms of percent ability, based upon the following equation: $2,3,5-$ triphenyltetrazolium chloride reduction $(\%)=\left(\mathrm{T}_{1}-\mathrm{T}_{2}\right) /\left(\mathrm{C}_{1}-\right.$ $\left.C_{2}\right) \times 100$, where $T_{1}$ is for treated samples, $T_{2}$ for 'heated' treated samples, $\mathrm{C}_{1}$ for control samples, $\mathrm{C}_{2}$ for 'heated' control samples.

\subsection{Field experiment}

The plants were raised in earthen pots $(30 \mathrm{~cm}$ height, $25 \mathrm{~cm}$ diameter, $14.72 \mathrm{~L}$ volume) with a mixture of air-dried soil, sand and farm yard manure in a ratio of 2:1:1 (v/v). The soil was loam with a pH of 7.1 and available $\mathrm{N}, \mathrm{P}$ and $\mathrm{K}$ at 54,43 and $158 \mathrm{~kg} \mathrm{ha}^{-1}$, respectively. The seeds were inoculated with Rhizobium ciceri at the recommended rate of $1.95 \mathrm{~g} \mathrm{~kg}^{-1}$ seed. 4 seeds were planted in each pot in November and after emergence, the plants were thinned to 2 per pot. The plants were grown in glasshouse conditions (temperature $-28 / 12^{\circ} \mathrm{C}$, as 
average maximum and minimum temperature; light intensity $1400 \mu \mathrm{mol} \mathrm{m} \mathrm{s}^{-2} \mathrm{~s}^{-1}$; relative humidity $60-65 \%$ ). In the first and third weeks of December, corresponding to the bud and podfilling stages, respectively, glasshouse-grown plants were given foliar application of $1 \mathrm{mM}$ glycine betaine along with $0.01 \%$ Tween-20 as a wetting agent for 3 consecutive days. In a preliminary trial, we evaluated 1,5 and $10 \mathrm{mM}$ concentrations of glycine betaine using yield traits. While $10 \mathrm{mM}$ reduced the vegetative growth, induced floral abortion and decreased the yield over stressed plants, $5 \mathrm{mM}$ was effective only for improving floral retention and pod set. $1 \mathrm{mM}$ was found to be most effective for significant increase in almost all the traits examined. Hence, it was chosen for foliar application. These treated plants were moved to the chilling temperatures $\left(12-14 / 3-5^{\circ} \mathrm{C}\right.$; day/night) of the field along with controls. The samples for biochemical and flower functioning tests were collected at $8.00 \mathrm{am}$.

\subsection{Glycine betaine}

Aliquots of powder from plant tissue $(1 \mathrm{~g})$ stored at freezing temperatures were weighed and put into $1.5-\mathrm{mL}$ centrifuge tubes with $50 \mu \mathrm{L}$ of drying reagent $[5 \%(\mathrm{w} / \mathrm{v})$ silver orthophosphate in anhydrous disodium hydrogen phosphate] followed by $1 \mathrm{~mL}$ of extraction solvent $[10 \%(\mathrm{v} / \mathrm{v})$ methanol and $90 \%(\mathrm{v} /$ v) anhydrous acetonitrile (Lever et al., 1992). Samples were mixed for $10 \mathrm{~min}$, centrifuged at $12000 \mathrm{~g}$ for $3 \mathrm{~min}$ and then an aliquot of the supernatant $(200 \mu \mathrm{L})$ was transferred to a fresh tube containing $20 \mu \mathrm{L}$ of a $10 \%(\mathrm{w} / \mathrm{v})$ suspension of magnesium oxide in water. After mixing, $50 \mu \mathrm{L}$ of derivatizing agent (4isomohenacyl triflate) was added. The mixing continued for an additional $1 \mathrm{~min}$ after which the mixture was centrifuged for $5 \mathrm{~min}$ at $12000 \mathrm{~g}$ and aliquots $(10 \mu \mathrm{L})$ of the supernatant injected directly into a $100 \times 4.6 \mathrm{~mm}(5 \mu \mathrm{m})$ silica column and eluted with a solvent phase of $1.6 \mathrm{mM}$ citric acid in $40 \mathrm{mM}$ triethanolamine (15\%): isopropanol $(85 \%)$. The detection was done at $260 \mathrm{~nm}$ with an ultraviolet detector. Standards were run using derivatized glycine betaine (sigma).

\subsection{Relative leaf water content}

The topmost leaves were excised from the plant and their fresh weight ( $2 \mathrm{~g}$ ) was recorded. The leaves were floated on distilled water for $2 \mathrm{~h}$ in a petri-dish. They were taken out and surface-dried with blotters and weighed (turgid weight). These were oven-dried at $110^{\circ} \mathrm{C}$ and weighed again (dry weight). The relative leaf water content was calculated according to Weatherley (1950) as follows:

Relative Leaf Water Content $=\frac{\text { Fresh wt. }- \text { Dry wt. }}{\text { Turgid wt. }- \text { Dry wt. }} \times 100$.

\subsection{Chlorophyll}

The topmost fresh leaves $(1 \mathrm{~g})$ were extracted with $80 \%$ acetone and centrifuged at $5000 \mathrm{~g}$ for $10 \mathrm{~min}$. The absorbance of the supernatant was read at 645 and $663 \mathrm{~nm}$ and calculated for total chlorophyll (Arnon, 1949).

\subsection{Endogenous ABA and sucrose}

These were quantified according to the methods of Wang et al. (2002) and Liu and van Staden (2001), respectively, and elaborated elsewhere (Nayyar et al., 2005).

\subsection{Lipid peroxidation}

This was measured in terms of malondialdehyde content, a product of lipid peroxidation according to the method of Heath and Packer (1968). The leaf samples (1 g) were homogenized in $10 \mathrm{~mL}$ of $0.1 \%$ trichloroacetic acid. The homogenate was centrifuged at $15000 \mathrm{~g}$ for $5 \mathrm{~min} .4 \mathrm{~mL}$ of $0.5 \%$ thiobarbituric acid in $20 \%$ trichloroacetic acid was added to a $1-\mathrm{ml}$ aliquot of the supernatant. The mixture was heated at $95{ }^{\circ} \mathrm{C}$ for $30 \mathrm{~min}$ and then quickly cooled in an ice bath. After centrifugation at $10000 \mathrm{~g}$ for $10 \mathrm{~min}$, the absorbance was recorded at $532 \mathrm{~nm}$. The value for non-specific absorption at $600 \mathrm{~nm}$ was subtracted. The malondialdehyde content was calculated using its absorption coefficient of $155 \mathrm{mmol}^{-1} \mathrm{~cm}^{-1}$ and expressed as nmol malondialdehyde $\mathrm{g}^{-1}$ fresh weight.

\subsection{Hydrogen peroxide}

This was measured in leaf tissues $(1 \mathrm{~g})$ using titanium reagent according to Teranishi et al. (1974). $1 \mathrm{~g}$ of titanium dioxide and $10 \mathrm{~g}$ of potassium sulphate were mixed and digested with $150 \mathrm{~mL}$ of concentrated sulfuric acid for $2 \mathrm{~h}$ on a hot plate. The digested mixture was cooled and diluted to make $15 \mathrm{~mL}$ with distilled water and used as a titanium reagent. Sample preparation and hydrogen peroxide estimation were done as described previously (Prasad et al., 1994).

\subsection{Flower function}

About 100 flowers taken from 25 plants were investigated for flower function. Pollen grains were tested for viability (Alexander, 1969), germination and tube growth under in vitro (Brewbaker and Kwack, 1963) and in vivo conditions (Martin, 1959). The flowers were also examined for stigma receptivity (Mattson et al., 1974) and ovule viability (Dumas and Knox, 1990). Flowering \% was calculated by dividing the total number of flowers formed by total number of buds produced multiplied by one hundred. Flower retention $\%$ was calculated by dividing the number of flowers retained by total number of flowers produced multiplied by one hundred. Pod set $\%$ was determined by dividing the number of pods set by total number of retained flowers multiplied by one hundred. Pod retention $\%$ was calculated by dividing the number of pods retained by total number of pods produced multiplied by one hundred. The percentage of infertile pods was determined by dividing the number of seedless pods with total number of pods (fertile and infertile) produced multiplied by one hundred.

\subsection{Yield traits}

50 plants were examined for seed yield $(\mathrm{g})$ plant $^{-1}$, seeds 100 pods $^{-1}$, seed weight $\left(\mathrm{mg} \mathrm{seed}{ }^{-1}\right)$, and single-seeded and double-seeded pods. 


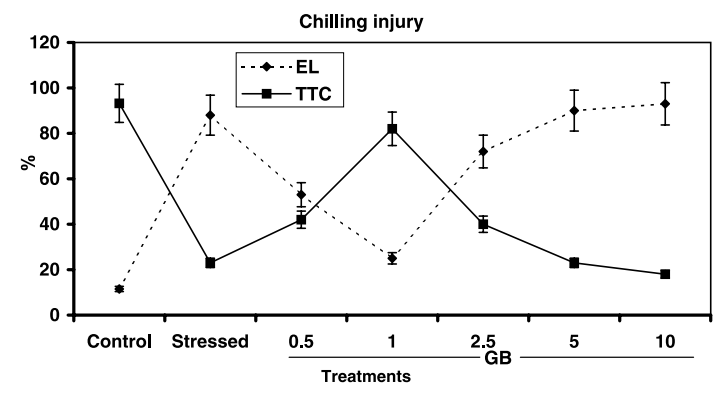

Figure 1. Evaluation of different concentrations of glycine betaine (GB) on chilling injury. 12-day-old seedlings growing hydroponically were subjected to $5^{\circ} \mathrm{C}\left(\mathrm{LT}_{50}\right)$ in the presence of 0.5 to $10 \mathrm{mM}$ glycine betaine. Chilling injury was assessed on 7 th day of stress as electrolyte leakage (EL; \%) and triphenyltetrazolium chloride (TTC) reduction activity. Mean \pm SE (vertical bars). LSD (0.05) for EL and TTC are 4.8 and 3.9 , respectively. $*$ Significantly different $(0.05)$ from untreated stressed plants. Control-unstressed.

The experiments were conducted in 3 replications following a completely randomized block design and statistically analyzed. For each biochemical parameter and relative leaf water content, the samples were collected at $8.00 \mathrm{am}$. Mean values were pooled and standard error (S.E.) was calculated. The data represent mean values \pm S.E. All data were subjected to an analysis of variance. The difference between the mean values of treatments was estimated using least significant difference (L.S.D.) at the 0.05 level of significance.

\section{RESULTS AND DISCUSSION}

\subsection{Evaluation of varying concentrations of glycine betaine on chilling injury}

In a preliminary experiment, 12-d-old chickpea seedlings were subjected to $5^{\circ} \mathrm{C}\left(\mathrm{LT}_{50}\right)$ in the presence of 0.5 to $10 \mathrm{mM}$ concentrations of glycine betaine. Among various concentrations of glycine betaine, $1 \mathrm{mM}$ was found to be the best since it resulted in maximum decrease in electrolyte leakage $(63 \%)$ while triphenyltetrazolium chloride reduction ability showed $59 \%$ increase over untreated stressed seedlings (Fig. 1). Higher concentrations proved to be inhibitory (Fig. 1).

\subsection{Effect of exogenous GB on endogenous GB levels, chilling injury and relative leaf water content}

The stressed plants increased their glycine betaine content more than twofold on the 4th day of stress compared with the 1st day of stress but it began to decline rapidly thereafter (Fig. 2). Foliar application of glycine betaine raised its endogenous level more than threefold over controls on the 7 th day of stress, indicating its substantial uptake from leaves. Control plants showed very low values of glycine betaine (2.7$3.1 \mu \mathrm{mol} \mathrm{g} \mathrm{dW}^{-1}$ ). Chilling injury increased with stress period and was maximum (88\%) on the 7th day (Fig. 2) in untreated stressed plants, whereas glycine betaine-treated plants showed $63 \%$ reduction in chilling injury over stressed plants on this
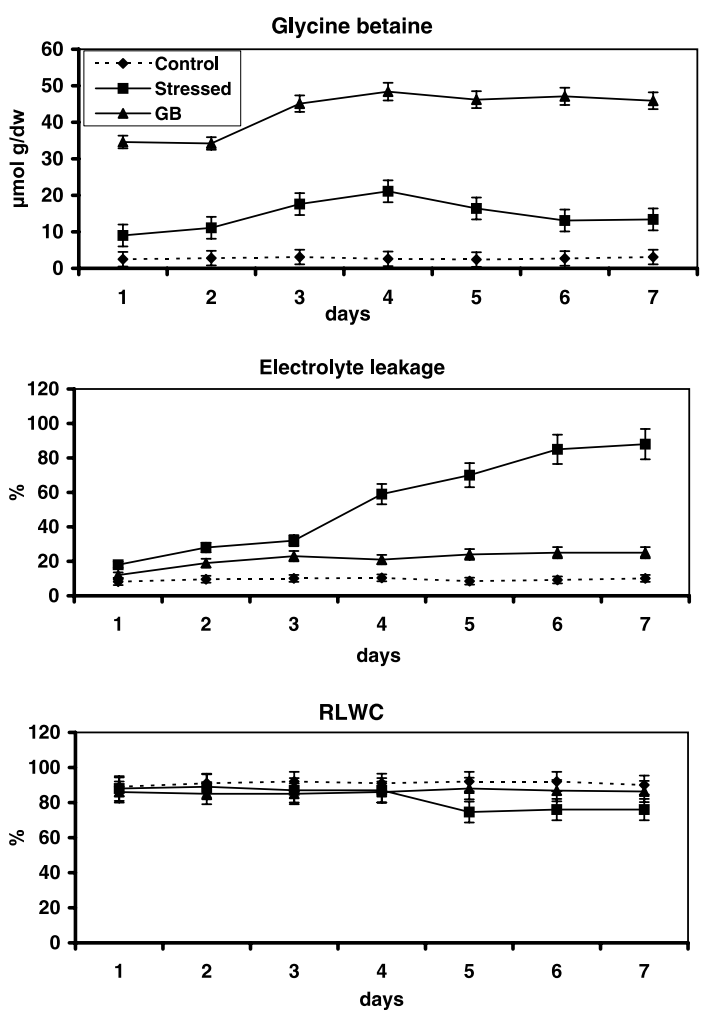

Figure 2. Effect of foliar application of glycine betaine (GB; $1 \mathrm{mM}$ ) on endogenous GB levels, chilling injury (electrolyte leakage) and relative leaf water content (RLWC). The plants previously growing under warmer glasshouse $\left(28 / 12{ }^{\circ} \mathrm{C}\right)$ conditions were subjected to cold stress in field conditions $\left(12-14 / 3-5{ }^{\circ} \mathrm{C}\right.$; maximum and minimum temperature, respectively) at the bud stage. Prior to stress, the plants were foliar sprayed with GB for 3 consecutive days. Observations were recorded for 7 days from topmost leaves. Mean $\pm S E$ (vertical bars). A- LSD (0.05) for control, stressed and GB-treated are 0.3, 4.2 and 3.6, respectively; B- LSD (0.05) for control, stressed and GBtreated are 3.1, 3.6 and 4.3, respectively; C- LSD (0.05) for control, stressed and GB-treated are 3.2, 3.4 and 2.6, respectively. * Significantly different (0.05) from untreated stressed plants.

day. In stressed plants, relative leaf water content showed significant reduction (12-13\%) beginning from the 5th day of stress (Fig. 2) while application of glycine betaine raised the relative leaf water content significantly.

\subsection{Effect of exogenous glycine betaine on chlorophyll, sucrose and abscisic acid}

Chlorophyll began to decline significantly on the 4th day in untreated stressed plants and reached half of its value on the 7 th day while glycine betaine-treated plants did not show any appreciable loss of chlorophyll during this period (Fig. 3). Sucrose levels began to decrease in stressed plants on the 3 rd day and eventually had $50 \%$ reduction on the 7 th day while glycine betaine-treated plants had only $17 \%$ reduction. On the last day of stress, glycine betaine-treated plants possessed $65 \%$ more sucrose than control (Fig. 3). In control plants, sucrose content remained lower than glycine betaine-treated plants but showed higher content than stressed plants from the 5 th to 

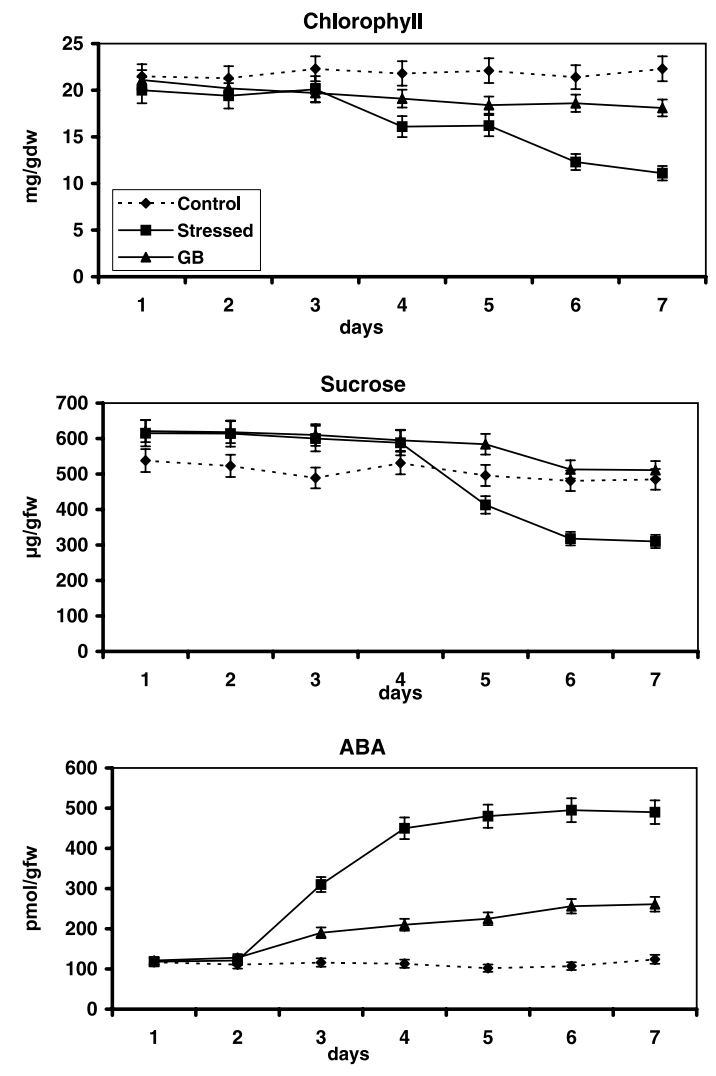

Figure 3. Effect of foliar application of glycine betaine (GB; $1 \mathrm{mM})$ on total chlorophyll, sucrose and abscisic acid (ABA) levels (details as in Fig. 2). Mean \pm SE (vertical bars). A- LSD (0.05) for control, stressed and GB-treated are 1.8, 2.3 and 2.5, respectively; B- LSD (0.05) for control, stressed and GB-treated are 8.2, 7.3 and 6.5, respectively; C- LSD (0.05) for control, stressed and GB-treated are 5.6, 4.8 and 6.1 , respectively. ${ }^{*}$ Significantly different $(0.05)$ from untreated stressed plants.

7th days. Abscisic acid was elevated in stressed plants by almost 4 times on the 6 th day from the 1 st day relative to a twofold increase in glycine betaine-treated plants (Fig. 3). Abscisic acid content was comparatively much lower in control plants.
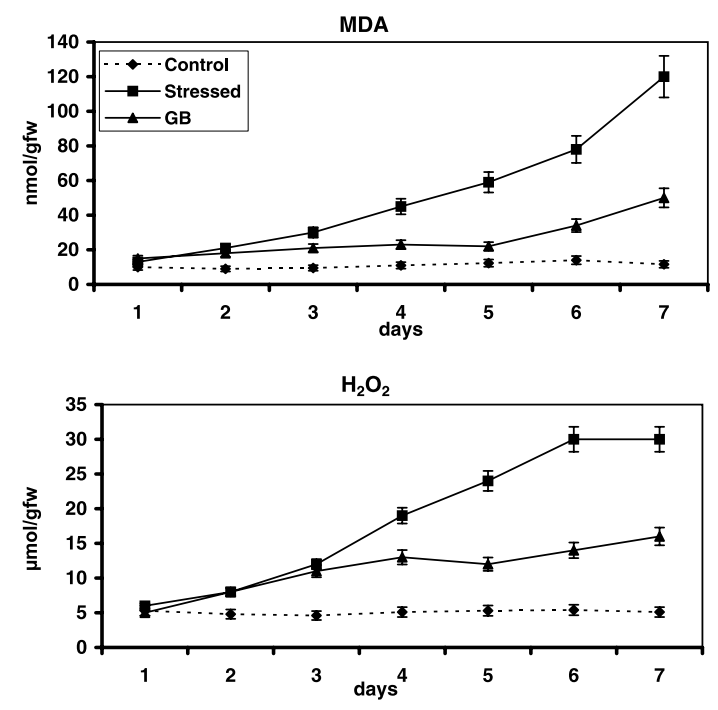

Figure 4. Effect of foliar application of glycine betaine (GB; $1 \mathrm{mM})$ on malondialdehyde (MDA) and hydrogen peroxide $\left(\mathrm{H}_{2} \mathrm{O}_{2}\right)$ levels (details as in Fig. 2). Mean \pm SE (vertical bars). A- LSD (0.05) for control, stressed and GB-treated are 2.1, 2.8 and 3.1, respectively; B- LSD $(0.05)$ for control, stressed and GB-treated are 2.3, 2.4 and 2.8, respectively. * Significantly different $(0.05)$ from untreated stressed plants.

\subsection{Effect of glycine betaine on reactive oxygen species}

On 7th day, glycine betaine-treated plants experienced a threefold increase in malondialdehyde (indicator of lipid peroxidation) and hydrogen peroxide contents over control as compared with eight- and fivefold increases, respectively, in untreated stressed plants. (Fig. 4).

\subsection{Effect of glycine betaine on flower functioning}

The pollen grains of stressed flowers showed 41 and $21 \%$ germination under in vitro and in vivo conditions, respectively, compared with 92 and $88 \%$ in unstressed controls (Tab. I). Application of glycine betaine raised the in vitro and in vivo

Table I. Effect of foliar application of $1 \mathrm{mM}$ glycine betaine (GB) on flower function. The plants previously growing under warmer glasshouse $\left(28 / 12{ }^{\circ} \mathrm{C}\right)$ conditions were subjected to cold stress in field conditions $\left(12-14 / 3-5{ }^{\circ} \mathrm{C}\right.$; maximum and minimum temperature, respectively) at the bud stage. Prior to stress, the plants were foliar sprayed with GB for 3 consecutive days. About 100 flowers from 25 plants were analyzed for different tests. Values represent mean \pm S.E. Figures in parenthesis indicate $\%$ increase with GB over untreated stressed plants.

\begin{tabular}{|c|c|c|c|c|c|c|c|}
\hline \multirow[t]{2}{*}{ Treatment } & \multicolumn{2}{|c|}{ Pollen G (\%) } & \multirow[t]{2}{*}{ Pollen viability (\%) } & \multicolumn{2}{|c|}{ Pollen tube growth $(\mu \mathrm{m})$} & \multirow{2}{*}{$\begin{array}{l}\text { Stigma receptivity } \\
(1-5 \text { scale })\end{array}$} & \multirow{2}{*}{$\begin{array}{l}\text { Ovule viability } \\
\left(\Delta \mathrm{A}_{560} \mathrm{~g} \mathrm{fw}^{-1}\right)\end{array}$} \\
\hline & In vivo & In vitro & & In vivo & In vitro & & \\
\hline Control & $92 \pm 2.5$ & $88 \pm 3.1$ & $93 \pm 3.1$ & $21.4 \pm 1.8$ & $45.2 \pm 2.4$ & $4.8 \pm 1.2$ & $85.2 \pm 2.5$ \\
\hline Stressed & $41.6 \pm 2.3$ & $21.4 \pm 2.6$ & $58.3 \pm 2.9$ & $9.2 \pm 2.8$ & $21.9 \pm 3.1$ & $2.6 \pm 0.9$ & $41.6 \pm 2.9$ \\
\hline GB-Treated & $83.1 \pm 3.1(99.7)$ & $53.2 \pm 2.8(148)$ & $78.2 \pm 3.4(34)$ & $17.2 \pm 3.5(86)$ & $39.2 \pm 3.7(79)$ & $3.8 \pm 1.4(46)$ & $73.2 \pm 2.7(76)$ \\
\hline L.S.D. (0.05) & 3.8 & 4.5 & 4.2 & 3.2 & 3.1 & 1.1 & 5.6 \\
\hline
\end{tabular}


Table II. Effect of foliar application of $1 \mathrm{mM}$ glycine betaine (GB) on number of flowers and pods. The plants previously growing under warmer glasshouse $\left(28 / 12{ }^{\circ} \mathrm{C}\right)$ conditions were subjected to cold stress in field conditions $\left(12-14 / 3-5{ }^{\circ} \mathrm{C}\right.$; maximum and minimum temperature, respectively) at the bud stage. Prior to stress, the plants were foliar sprayed with GB for 3 consecutive days. About 100 buds and flowers from 25 plants were tagged for different parameters. Values represent mean \pm S.E. Figures in parenthesis indicate \% increase or decrease with GB over untreated stressed plants.

\begin{tabular}{lcccc}
\hline Parameter & Control & Stressed & GB-Treated & $\begin{array}{c}\text { L.S.D. } \\
(0.05)\end{array}$ \\
\hline Flowering \% & $89.1 \pm 2.3$ & $23.4 \pm 1.4$ & $53.2 \pm 2.3(30)$ & 4.6 \\
Flowering retention \% & $91.2 \pm 2.6$ & $22.1 \pm 1.6$ & $69.2 \pm 1.8(47)$ & 5.2 \\
Pod set \% & $88.1 \pm 3.1$ & $18.2 \pm 1.8$ & $56.2 \pm 2.3(38)$ & 4.1 \\
Pod retention \% & $86.2 \pm 3.4$ & $43.1 \pm 2.3$ & $66.1 \pm 2.1(23)$ & 3.2 \\
Infertile pods \% & $8.2 \pm 2.4$ & $54.1 \pm 2.7$ & $23.2 \pm 1.8(30.9)$ & 3.4 \\
\hline
\end{tabular}

pollen germination to 83 and $53 \%$, respectively. The pollen viability of stressed flowers was $58 \%$, which was increased to $78 \%$ with glycine betaine. The pollen tubes of glycine betainetreated plants showed a marked increase over untreated stressed plants under in vivo (86\%) and in vitro (79\%) conditions. The stigma receptivity and ovule viability increased by 46 and $76 \%$, respectively, in glycine betaine-treated plants compared with stressed ones.

\subsection{Effect of glycine betaine on yield traits}

Application of glycine betaine to stressed plants increased the flowering to $53 \%$ compared with $23 \%$ in untreated plants (Tab. II). The retention of flowers was increased by $47 \%$ while the pod set was improved by $38 \%$ over control with glycine betaine treatment. A $23 \%$ increase in pod retention was noticed in glycine betaine-treated plants relative to controls. The infertile pods were reduced by $30 \%$ with glycine betaine application. The seed yield (g) per plant increased by $28 \%$ in glycine betaine-treated plants over stressed plants while the number of seeds/100 pods increased to 62 in glycine betaine-treated plants as compared with 45 in untreated stressed plants (Tab. III). Individual seed weight increased significantly from $83 \mathrm{mg}$ in stressed plants to $91 \mathrm{mg}$ in glycine betaine-treated plants. The number of single- and double-seeded pods per plant was enhanced by glycine betaine from 6.2 and 4.1, respectively, to 11.1 and 6.2 , respectively.

The present studies indicate that exogenous application of glycine betaine imparts cold tolerance to chickpea, possibly due to substantiation of its endogenous levels that appear to be insufficient to counter the chilling injury. Cold-stressed chickpea plants treated with glycine betaine showed a marked increase in retention of their flowers and pods as well as almost all the yield traits. Earlier studies reported that plant species with less ability to accumulate glycine betaine could become cold-tolerant with exogenous glycine betaine application while glycine betaine accumulators were either not responsive or showed inhibition (Chen et al., 2000). Here, we found that glycine betaine application to cold-stressed plants also reduced the electrolyte leakage (indicator of membrane damage), chlorophyll loss (indicator of chloroplast damage) and increased the
Table III. Effect of foliar application of $1 \mathrm{mM}$ glycine betaine (GB) on number of flowers and pods. The plants previously growing under warmer glasshouse $\left(28 / 12{ }^{\circ} \mathrm{C}\right)$ conditions were subjected to cold stress in field conditions $\left(12-14 / 3-5{ }^{\circ} \mathrm{C}\right.$; maximum and minimum temperature, respectively) at the pod-filling stage. Prior to stress, the plants were foliar sprayed with GB for 3 consecutive days. 50 plants were examined for each parameter. Values represent mean \pm S.E. Figures in parenthesis indicate \% increase with GB over untreated stressed plants.

\begin{tabular}{lcccc}
\hline Parameter & Control & Stressed & GB-Treated & $\begin{array}{c}\text { L.S.D. } \\
(0.05)\end{array}$ \\
\hline Seed yield/Plants (g) & $7.8 \pm 1.3$ & $4.6 \pm 1.0$ & $5.9 \pm 1.6(28)$ & 1.8 \\
Seeds/100 pods & $88.1 \pm 2.6$ & $45.3 \pm 3.1$ & $62.1 \pm 2.6(37)$ & 2.8 \\
Seed weight (mg/seed) & $102 \pm 3.4$ & $83.1 \pm 2.8$ & $91.1 \pm 3.4(10)$ & 1.4 \\
Single-seeded pods/Plant & $14.1 \pm 2.4$ & $6.2 \pm 2.4$ & $11.1 \pm 2.7(77)$ & 1.7 \\
Double-seeded pods/Plant & $7.6 \pm 2.6$ & $4.1 \pm 2.1$ & $6.2 \pm 1.6(51)$ & 2.2 \\
\hline
\end{tabular}

triphenyltetrazolium chloride reduction ability (indicator of mitochondrial function). Earlier observations on this aspect reported protection of thylakoid membranes (Coughlam and Heber, 1982) and photosystems (Papageorgiou and Murata, 1995) by glycine betaine. The damage to cell membranes and their organelles (especially mitochondria and chloroplast) may arise from cold-induced oxidative stress (Nayyar and Kaushal, 2002). We found here that levels of reactive oxygen species such as malondialdehyde (indicator of lipid peroxidation) and hydrogen peroxide declined effectively with glycine betaine application, which might prevent damage to membranes. These findings are consistent with those of Chen et al. (2000) who also reported reduction in lipid peroxidation and membrane damage with glycine betaine in chilling-stressed maize plants.

Relative leaf water content showed a significant decrease due to cold stress, indicating water loss. This may occur due to chilling-induced reduction in the ability of the roots to supply water (McWilliam et al., 1982; Vernieri et al., 2001) and impaired stomatal function (Guye and Wilson, 1987). However, glycine betaine-treated plants maintained higher relative leaf water content that might be because of its role in turgor generation (Xing and Rajashekar, 1999). Elevation of abscisic acid in the present studies might occur due to chilling-induced water loss (Singh and Sawhney, 1998) or direct effects of cold (Kratsch and Wise, 2000). Glycine betaine application reduced the abscisic acid levels to almost half of that in untreated stressed plants in our studies, which might possibly be related to increase in water status by glycine betaine. Abscisic acid, though implicated in cold tolerance (Kratsch and Wise, 2000) is also reported to induce abscission of reproductive organs during stress conditions (Liu et al., 2003). These variations in effects of abscisic acid might be attributed to its endogenous levels. Earlier, in a related study, we reported higher abscisic acid levels in aborted flowers of chickpea than the retained ones (Nayyar et al., 2005).

Sucrose levels declined drastically in cold-stressed plants, which might be the result of damage to photosynthesis by chilling (Sonoike, 1998). In glycine betaine-treated plants, sucrose remained higher, possibly because of the protective effect of glycine betaine on different components of photosynthesis (Dioniso-Sese et al., 1999). Here, we found higher chlorophyll 
retention with glycine betaine in cold-stressed plants that indirectly indicated less damage to photosynthetic apparatus. Moreover, sucrose accumulation has cryoprotective significance too (Palonen et al., 2000) and its elevation in glycine betainetreated plants may add to cold tolerance.

The abnormalities in functioning of flowers might arise by effects of cold stress on flower development per se or on production and mobilization of photo-assimilates (Sonoike, 1998). Since abscisic acid levels have also been found to govern the fertility status of flowers (Singh and Sawhney, 1998), poor gamete functioning in our studies as well as the previous ones (Srinivasan et al., 1999) might be ascribed to its supra-optimal levels in stressed plants or their flowers (Nayyar et al., 2005). Glycine betaine application appears to restore the flower function to a significant extent, which might be associated with reduced abscisic acid but elevated sucrose levels at the same time.

The increase in retention of pods and decrease in number of infertile pods by glycine betaine might also be related to similar reasons. There was a significant increase in most of the yield traits with glycine betaine application but the number of double-seeded pods was not affected much. This might be due to the effect of glycine betaine on differential allocation of dry matter into various organs. The underlying mechanisms leading to improvement in yield by glycine betaine need more investigation before any sound conclusions can be drawn.

\section{CONCLUSION}

The findings presented here show that exogenous glycine betaine application induces partial cold tolerance in chickpea, which is reflected as an increase in floral retention, pod set and most of the yield parameters in cold-stressed plants. This might become possible through elevation of endogenous glycine betaine levels in this plant, which otherwise appears to be inherently deficient in glycine betaine accumulation.

The financial assistance from the University Grants Commission, India, for the present study is gratefully acknowledged. Thanks are due to my students for technical assistance.

\section{REFERENCES}

Alexander M.P. (1969) Differential staining of aborted and non-aborted pollen, Stain Tech. 44, 117-122.

Alia Hayashi H., Chen T.H.H., Murata N. (1998) Transformation with a gene for choline oxidase enhances the cold tolerance of Arabidopsis during germination and early growth, Plant, Cell Environ. 21, 232239.

Alia Hayashi H., Mustardy L., Deshnium P., Ida M., Murata N. (1997) Transformation of Arabidopsis thaliana with the codA gene for choline oxidase; accumulation of glycinebetaine and enhanced tolerance to salt and cold stress, Plant J. 12, 133-142.

Arnon D.I. (1949) Copper enzyme in isolated chloroplasts: Polyphenol oxidase in Beta vulgaris, Plant Physiol. 24, 1-15.

Brewbaker J.L., Kwack B.H. (1963) The essential role of calcium ion in pollen germination and pollen tube growth, Am. J. Bot. 50, 859865 .

Chen W.P., Li P.H., Chen T.H.H. (2000) Glycinebetaine increases chilling tolerance and reduces chilling-induced lipid peroxidation in Zea mays L., Plant Cell Environ. 23, 609-618.
Coughlam S.J., Heber U. (1982) The role of glycine betaine in the protection of spinach thylakoids against freezing stress, Planta 156,6269.

Croser J.S., Clarke H.J., Siddique K.H.M., Khan T.N. (2003) Low temperature stress: Implications for chickpea (Cicer arietinum L.) improvement, Critic. Rev. Plant Sci. 22, 185-219.

Dioniso-Sese M.L., Shono M., Tobita S. (1999) Effects of proline and betaine on heat inactivation of ribulose-1,5-bisphosphate carboxylase/oxygenase in crude extracts of rice seedlings, Photosynthetica $36,557-563$.

Dumas C., Knox R.B. (1990) Callose and determination of pistil viability and incompatibility, Theor. Appl. Genet. 67, 1-10.

Guye M.G., Wilson J.M. (1987) The effect of chilling and chill hardening temperatures on stomatal behaviour in chill-sensitive species and cultures, Plant Physiol. Biochem. 25, 717-721.

Heath R.L., Packer L. (1968) Photoperoxidation in isolated chloroplast. I. Kinetics and stochiometery of fatty acid peroxidation, Arch. Biochem. Biophys. 125, 189-198.

Kishitani S., Watanabe K., Yasuda S., Arakawa K., Takabe T. (1994) Accumulation of glycine betaine during cold accumulation and freezing tolerance in leaves of winter and spring barley plants, Plant Cell Environ. 17, 89-95.

Kratsch H.A., Wise R.R. (2000) The ultrastructure of chilling stress, Plant Cell Environ. 23, 337-350.

Lee C.B., Hayashi H., Moon B.Y. (1997) Stabilization by glycinebetaine of photosynthetic oxygen evolution by thylakoid membranes from Synechococcus PCC7002, Mol. Cells 7, 296-299.

Lee H., Xiong L., Ishitani M., Zhu J.K. (1999) Cold-regulated gene expression and freezing tolerance in an Arabidopsis thaliana mutant, Plant J. 17, 301-308.

Lever M., Bason L., Leaver C., Hayman C.M., Chambers S.T. (1992) Same-day batch measurements of carnitine and other betaines in biological material, Anal. Biochem. 205, 14-21.

Liu F., Andersen M.N., Jensen C.R. (2003) Loss of pod set caused by drought stress is associated with water status and ABA content of reproductive structures in soybean, Func. Pl. Biol. 30, 271-280.

Liu T., van Staden J. (2001) Partitioning of carbohydrates in salt-sensitive and salt-tolerant soybean callus cultures under salinity stress and its subsequent relief, Plant Growth Regul. 33, 13-17.

Lutts S., Kinet J.M., Bouharmont J. (1996) NaCl-induced senescence in leaves of rice (Oryza sativa L.) cultivars differing in salinity resistance, Ann. Bot. 78, 389-398.

Mäkelä P., Munns R., Colmer T.D., Condon A.G., Peltonen-Sainio P. (1998) Effect of foliar applications of glycine betaine on stomatal conductance, abscisic acid and solute concentrations in leaves of salt- or drought-stressed tomato, Aust. J. Plant Physiol. 25, 655663.

Martin F.W. (1959). Staining and observing pollen tubes in the style by means of fluorescence, Stain Tech. 34, 125-128.

Mattson O., Knox R.B., Heslop-Harrison J., Heslop-Harrison Y. (1974) Protein pellicle of stigmatic papillae as a probable recognition site in incompatibility reactions, Nature (London) 247, 298-300.

McNeil S.D., Nuccio M.L., Hanson A.D. (1999) Betaines and related osmoprotectants. Targets for metabolic engineering of stress resistance, Plant Physiol. 120, 945-949.

McWilliam J.R., Kramer P.J., Musser R.L. (1982) Temperature induced water stress in chilling sensitive plants, Aust. J. Plant Physiol. 9, $343-352$.

Mittler R. (2002) Oxidative stress, antioxidants and stress tolerance, Trends Plant Sci. 7, 405-410.

Nayyar H., Bains T., Kumar S. (2005) Low temperature induced floral abortion in chickpea: Relationship with abscisic acid and cryoprotectants in reproductive organs, Environ. Exp. Bot. 53, 39-47. 
Nayyar H., Kaushal S.K. (2002) Chilling induced oxidative stress in germinating wheat grains as affected by water stress and calcium, Biol. Plant. 45, 601-604.

Palonen P., Buszard D., Donnelly D. (2000) Changes in carbohydrates and freezing tolerance during cold acclimation of red raspberry cultivars grown in vitro and in vivo, Physiol. Plant. 110, 393-401.

Papageorgiou G.C., Murata N. (1995) The unusually strong stabilizing effects of glycine betaine on the structure and function of the oxygen-evolving photosystem II complex, Photosynth. Res. 44, 243252.

Prasad T.K., Anderson M.D., Martin B.A., Stewart C.R. (1994) Evidence for chilling-induced oxidative stress in maize seedlings and a regulatory role for hydrogen peroxide, Plant Cell 6, 65-74.

Rhodes D., Hanson A.D. (1993) Quaternary ammonium and tertiary sulfonium compounds in higher plants, Annu. Rev. Plant Physiol. Plant Mol. Biol. 44, 357-384.

Parker J. (1995) Some applications and limitations of tetrazolium chloride, Science 118, 77-79.

Roberts L.W. (1951) Survey of factors responsible for reduction of 2,3,5triphenyltetrazolium chloride in plant meristems, Science 113, 692-693.

Sakamoto A., Murata N. (2002) The role of glycine betaine in the protection of plants from Stress: clues from transgenic plants, Plant Cell Environ. 25, 163-172.

Singh K.B., Malhotra R.S., Saxena M.C. (1993) Relationship between cold severity and yield loss in chickpea (Cicer arietinum L.), J. Agron. Crop Sci. 170, 121-127.

Singh S., Sawhney V. (1998) Abscisic acid in a male sterile tomato mutant and its regulation by low temperature, J. Exp. Bot. 49, 199-203.
Sonoike K. (1998) Various aspects of inhibition of photosynthesis under light/chilling stress: photoinhibition at chilling temperatures versus chilling damage in light, J. Plant Res. 111, 121-129.

Srinivasan A., Johansen C., Saxena N.P. (1998) Cold tolerance during early reproductive growth of chickpea (Cicer arietinum L.): characterization of stress and genetic variation in pod set, Field Crops Res. 57, 179-191.

Srinivasan A., Saxena N.P., Johansen C. (1999) Cold tolerance during early reproductive growth of chickpea (Cicer arietinum L.) genetic variation in gamete development and function, Field Crops Res. 60, 209-222.

Steponkus P.L., Lanphear F.O. (1967) Refinement of the triphenyltetrazolium chloride method of determining cold injury, Plant Physiol. 42, 1423-1426.

Teranishi Y., Tanaka A., Osumi M., Fukui S. (1974) Catalase activity of hydrocarbon utilising candida yeast, Agr. Biol. Chem. 38, 12131216.

Vernieri P., Lenzi A., Figaro M., Tognoni F., Pardossi A. (2001) How the roots contribute to the ability of Phaseolus vulgaris L. to cope with chilling-induced water stress, J. Exp. Bot. 52, 2199-2206.

Wang Z., Mamabelli S., Setter T.L. (2002) Abscisic acid catabolism in maize kernels in response to water deficit at early endosperm development, Ann. Bot. 90, 623-630.

Weatherley P.E. (1950) Studies in the water relation cotton plants: The field measurement of water deficit in leaves, New Phytol. 49, 81-87.

Xing W., Rajashekar C.B. (1999) Alleviation of water stress in beans by exogenous glycine betaine, Plant Sci. 148, 185-195.

Xing W., Rajashekar C.B. (2001) Glycine betaine involvement in freezing tolerance and water stress is Arabidopsis thaliana, Environ. Exp. Bot. 46, 21-28. 